\title{
A Molecular Analysis Of Prion Protein Expression In Alzheimer's Disease
}

\author{
Alisdair McNeill*, BSc, MedSci
}

\begin{abstract}
In Prion Diseases, misfolding of neuronal prion protein (PrPC) to a pathogenic isomer (PrPSC) is associated with neuronal death. Previous pathological studies have demonstrated increased immunoreactivity of PrPC at $\mathrm{A} \beta$ plaques in Alzheimer's Disease, and it has been suggested that this either reflects a role for PrPC in the neuronal response to stress or is a feature of the neuropathogenesis of atypical subtypes of Alzheimer's disease. In this paper we utilised western blotting to examine the molecular characteristics of PrP in frozen Hippocampal tissue from 7 cases of Alzheimer's Disease in which prion protein expression was demonstrated by immunohistochemistry, before using Restriction Fragment Length Polymorphism (RFLP) methodology to define the genotype of the codon 129 polymorphism of PRNP in each case. We observed PrP accumulating as globular structures at A plaques, and within ependymal cells lining the lateral ventricle. Immunohistochemistry also showed that PrPC and Superoxide dismutase-1 where deposited in a similar pattern at A $\beta$ plaques. Western blotting revealed that PrP in Alzheimer's disease is composed of the same 208-residue peptide expressed in non-diseased brain. Quantitative western blot analysis demonstrated increased levels of PrPC in a short duration case of Alzheimer's Disease, while, in the remaining cases, levels of PrPC decreased in parallel with increasing disease duration and decreasing brain mass. RFLP genotyping revealed that all codon 129 genotypes $(\mathrm{M} / \mathrm{M}, \mathrm{M} / \mathrm{V}, \mathrm{V} / \mathrm{V})$ were represented in our study cohort. Our data suggest that increased levels of PrPC may account for PrP immunoreactivity at plaques in Alzheimer's disease, and that PrP deposition is not restricted to certain atypical subtypes of Alzheimer's disease.
\end{abstract}

KEY WORDS: Alzheimer's, Prion protein, Immunohistochemistry, Western Blotting

\section{INTRODUCTION}

In the Prion diseases (Creutzfeldt-Jakob Disease, Kuru, Gerstmann-Straussler-Scheinker Syndrome and Fatal Familial Insomnia) a post-translational conformational change in neuronal prion protein (PrPC) to a $\beta$-sheet rich isomer termed PrPSC is associated with neuronal death (1). It is proposed that this process induces neurodegeneration either via production of neurotoxic PrPSC, or by ablation of the physiological function of PrPC (1).

The physiological role of PrPC remains unresolved, however, studies of PrP null mice have shown that it

* To whom correspondence should be addressed: 11 Broomieknowe Park, Bonnyrigg, Midlothian, EH19 2JB

email: s9809172@sms.ed.ac.uk is not essential for viability and various investigators have suggested that it may have a function in sleep regulation (2), cell adhesion (3) or Purkinje cell viability (4). More recently, in vitro studies showing that PrP-/- neurons are excessively vulnerable to oxidative stress, and that PrPC has a superoxide dismutase-1 (SOD-1) like activity $(5,6)$, have lead to the proposal that PrPC might have a role in the cellular response to oxidative stress. It is suggested that ablation of this anti-oxidant function of PrPC might be associated with neurodegeneration in Prion disease (6).

In Alzheimer's disease (AD) the neuronal $\beta$ Amyloid Precursor Protein ( $\beta$-APP) is aberrantly processed, causing extracellular deposition of its 
Table 1. Autopsy Material Used For Immunohistochemistry and Western Blotting

\begin{tabular}{clccl}
\hline Case Number & Age/Sex & Diagnosis & Disease Duration $(\mathbf{y})$ & Cause of Death \\
\hline 1 & $67 / \mathrm{F}$ & $\mathrm{AD}$ & N/A & Pneumonia \\
2 & $69 / \mathrm{M}$ & $\mathrm{AD}$ & 15 & Pneumonia \\
3 & $66 / \mathrm{F}$ & $\mathrm{AD}$ & 3 & Pneumonia \\
4 & $73 / \mathrm{F}$ & $\mathrm{AD}$ & 4 & Pneumonia \\
5 & $42 / \mathrm{F}$ & $\mathrm{AD}$ & 4 & Pneumonia \\
6 & $80 / \mathrm{F}$ & $\mathrm{AD}$ & 3 & Pneumonia \\
7 & $60 / \mathrm{M}$ & $\mathrm{AD}$ & 2 & Pneumonia \\
8 & $82 / \mathrm{F}$ & $\mathrm{AD}$ & N/A & Pneumonia \\
9 & $64 / \mathrm{M}$ & $\mathrm{AD}$ & 11 & Pneumonia \\
10 & $90 / \mathrm{F}$ & $\mathrm{AD}$ & N/A & TBI \\
11 & $25 / \mathrm{M}$ & TBI & N/A & Haemorrhage \\
12 & $66 / \mathrm{F}$ & N/A & Cardiomyopathy \\
13 & $32 / \mathrm{M}$ & Old Infarcts,SAH & Myocarditis \\
14 & $22 / \mathrm{F}$ & Cardiomyopathy & N/A & N/A \\
\hline
\end{tabular}

transmembrane domain. This peptide is designated $\mathrm{A} \beta$ and aggregates into neurotoxic $\mathrm{A} \beta$ plaques. Previous pathological studies have demonstrated that PrPC deposition occurs at A $\beta$ plaques in Alzheimer's disease (7,8). Voigtlander and colleagues (7) postulated that this phenomenon might reflect a role for PrPC in the neuronal response to oxidative stress induced by reactive oxygen species (ROS) produced by the A $\beta$-peptide. However, as PRNP mutations have been reported in familial AD kindreds (9), and PRNP codon 129 valine homozygosity increases risk of early onset $\mathrm{AD}$ in patients with a family history of AD (10), it is also possible PrPC immunostaining is a feature of atypical neuropathogenesis in certain subtypes of AD (11).

In this study we sought to investigate whether PrP deposition at $\mathrm{A} \beta$ plaques in Alzheimer's disease is a general phenomenon, possibly representing an antioxidant function of PrPC, or restricted to certain atypical cases. To this end, we utilised immunohistochemistry to analyse PrP deposition in paraffin embedded Hippocampal tissue from 9 sporadic and 1 familial case of Alzheimer's disease. We hypothesised that if PrP deposition at $\mathrm{A} \beta$ plaques was restricted to subtypes of Alzheimer's disease then immunostaining would only be seen in some of the Alzheimer's cases. Furthermore, the influence of the codon 129 polymorphism of PRNP was examined by restriction fragment length polymorphism (RFLP) genotyping of 7 cases of AD in which PrPC expression had been demonstrated. We then performed immunohistochemistry to examine the expression of the anti-oxidant enzyme SOD-1, which is known to be induced by oxidative stress in $\mathrm{AD}$, hypothesising that an anti-oxidant PrPC would be deposited in a similar pattern to SOD-1 in AD brain. Western blotting was then utilised to investigate the hypotheses that PrP immunostaining of $A \beta$ plaques reflects either increased levels of PrP or the presence of a bioactive PrP which is structurally distinct from, and more immunoreactive than PrPC.

$\mathrm{AD}$ is the most common cause of dementia in the Western World (around 20\% of those age 65 or over are affected) (12), and is the fourth leading cause of death (12). With our ageing population, AD is set to cause an increasing burden of ill health and healthcare costs. Current treatments for AD are only partly effective, and there is no cure or proven preventative strategy (12). Studying the neuropathological changes associated with $\mathrm{A} \beta$ plaque formation will increase our understanding of the processes leading to neuronal death, and hopefully suggest new therapeutic targets.

\section{METHODS}

\section{Cases for study}

Formalin-fixed, paraffin-embedded Hippocampal tissue from 10 cases of Alzheimer's disease (age range 42 - 90 years, mean 69.3 years, SD 13 years) and 3 neuropsychologically normal controls (age range 25 66 years, mean 40 years old, SD 23 years) were selected for study (Table 1). The cases were from the pathology archives of the Western General Hospital, Edinburgh. Cases were randomly selected from lists of cases with the desired diagnosis.

\section{Immunohistochemistry (IHC)}

For IHC analysis $5 \mu \mathrm{M}$ sections were cut from fixed brain tissue blocks in all cases. Sections were mounted on glass slides (Superfrost Plus; BDH, Poole, UK), dewaxed, rehydrated and endogenous peroxidases quenched in $3 \%$ hydrogen peroxide in methanol for 30 minutes. The primary antibodies, dilutions and antigen retrieval methods used in this 
Table 2. Primary Antibodies Used For Immuhistochemistry

\begin{tabular}{|c|c|c|c|c|}
\hline Antibody & Antigen & Source & $\begin{array}{l}\text { Incubation } \\
\text { Period } \\
\text { [conc.] }\end{array}$ & $\begin{array}{l}\text { Antigen } \\
\text { Retrieval }\end{array}$ \\
\hline $6 \mathrm{~F} / 3 \mathrm{D}$ & $(\mathrm{A} ß)$ & DAKO & $\begin{array}{l}30 \mathrm{~min} \\
{[1: 100]}\end{array}$ & FA. MW. \\
\hline AT8 & (Tau) & Autogen & $\begin{array}{l}30 \mathrm{~min} \\
{[1: 3000]}\end{array}$ & None \\
\hline $\mathrm{Ab} 1$ & $\begin{array}{l}(\mathrm{Cu} / \mathrm{Zn} \\
\text { SOD })\end{array}$ & Bioquots & $\begin{array}{l}\text { Overnight } \\
{[1: 1000]}\end{array}$ & FA. MW \\
\hline $3 \mathrm{~F} 4$ & $(\mathrm{PrP})$ & DAKO & $60 \mathrm{~min}$ & FA. M \\
\hline
\end{tabular}

study are summarised in Table 2. For PrP IHC, antigen retrieval was performed by microwaving in citrate buffer $(7 \mathrm{mM}(\mathrm{pH} 6.0))$ for 30 minutes at 450 W. Sections were then washed in Tris-buffered saline (TBS; $20 \mathrm{mM}$ Tris-HCl ( $\mathrm{pH}$ 7.6)) before incubation in $20 \%$ normal rabbit serum in TBS for 30 minutes. Sections of hippocampus were then exposed to the anti-PrP monoclonal antibody 3F4 (Dako, Glostrup, Denmark), diluted in $20 \%$ normal rabbit serum in TBS, for one hour. After primary antibody incubation, sections were repeatedly rinsed in TBS before being incubated with biotinylated rabbit antimouse antibody (SAPU, Edinburgh, UK) diluted 1:200 in normal rabbit serum in TBS, for 30 minutes at room temperature. The staining pattern was then visualised using the Catalysed Signal Amplification system (CSA, Dako). Sections were then counterstained in haematoxylin before mounting in DPX (BDH, Poole, UK).

Adjacent tissue sections were exposed to antibodies raised against the $\mathrm{A} \beta$ peptide $(6 \mathrm{~F} / 3 \mathrm{D}$, Dako, Glostrup, Denmark), tau (AT8, Autogen) and SOD-1 (AB1, Bioquote). Sections were prepared as for PrP IHC. No antigen retrieval was performed for tau. For the $\mathrm{A} \beta$ and tau antibodies the staining pattern was visualised using a standard avidin-biotin method (ABC Kit, Vector), with 3,3'-diaminobenzidine tetrahydro-chloride (Vector, CA, USA) as the chromogen. For SOD-1 the CSA system (DAKO) was used. For all antibodies controls were performed where the primary antibody was omitted. The stained sections were examined microscopically, and images captured using a Roper Scientific Photometrics camera and Image Pro 4.5 Cool Snap Software.

\section{Western Blotting}

For Western blotting, frozen tissue was available for cases 1 - 7 of Alzheimer's disease. Hippocampal tissue $(50-100 \mathrm{mg}$ ) was dissected out from each case and homogenised in 10 volumes (w/v) of protein extraction buffer. The homogenate was then centrifuged at 3,000 RPM at 40C for 10 minutes, and the supernatant and pellet stored at -700C. The homogenised protein was normalised using a Bio-Rad protein assay with bovine serum albumin as a standard, to ensure each sample contained the same quantity of protein. Glycosylation of $\operatorname{PrP}$ was examined by incubating homogenate with PNGase-F, following manufacturer's protocols, and Proteinase $\mathrm{K}$ sensitivity determined by treating homogenate with Proteinase $\mathrm{K}$.

Protein was separated by SDS-PAGE, using $12 \%$ Resolving Gel and 4\% Stacking Gel, on a Hoeffer Scientific Instruments "Mighty Small" gel running apparatus. Gels were stained with Coomasie blue to allow visualisation of protein expression profiles, or transferred to a Hybond-P (Amersham) membrane.

The transfer was performed at $100 \mathrm{~V}$, for 60 minutes in a Bio-Rad transfer apparatus. The membrane was first soaked in methanol for one minute, and then rinsed in distilled water. Both gel and membrane were then immersed in transfer buffer for 5 minutes before being sandwiched between sheets of blotting paper, and placed in the transfer apparatus filled with transfer buffer along with a cooling block.

After transfer, the membrane was blocked in 5\% fat-free milk solution overnight at 40C. After blocking, the membrane was rinsed in TBS-T and incubated with primary antibody (3F4, Dako, Glostrup, Denmark) for 60 minutes. The membrane was then rinsed in TBS-T, before incubation with anti-mouse-HRP antibody. Detection was then performed using an Amersham ECL-plus Chemiluminescence kit, following manufacturer's instructions.

\section{Restriction Fragment Length Polymorphism Genotyping Of Codon 129 Of PRNP}

DNA was extracted from the seven AD cases where frozen tissue was available, using the GenElute DNA extraction kit (Sigma). The eluted DNA was used as a template in a polymerase chain reaction (PCR) performed to amplify a $932 \mathrm{bp}$ fragment of PRNP, which included the open reading frame (ORF). The ORF was amplified from $2 \mu \mathrm{L}$ of eluted DNA using TAQ polymerase (Sigma), following manufacturer's instructions, with a reaction cycle consisting of 35 cycles of one minute at 940C followed by one cycle of one minute at $500 \mathrm{C}$ and one cycle of one minute at $720 \mathrm{C}$ on a Qiagen Omnigene PCR machine.

Codon 129 may be either the sequence (C)AUG(G), 

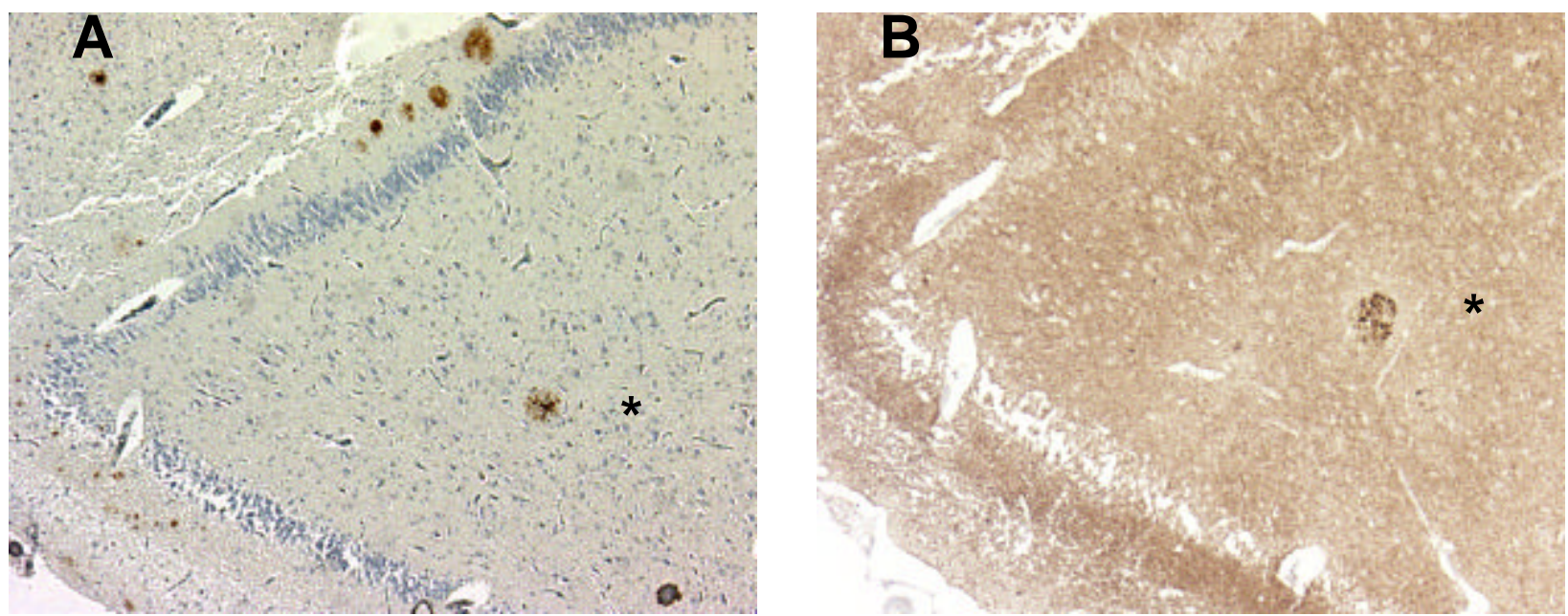

Figures 1. Pattern of PrP Deposition in AD and DS. A. Diffuse Aß plaque $(*)$ colocalising with: B. Globular PrP deposits $(*)$, C. PrP immunoreactive ependyma (arrowed).

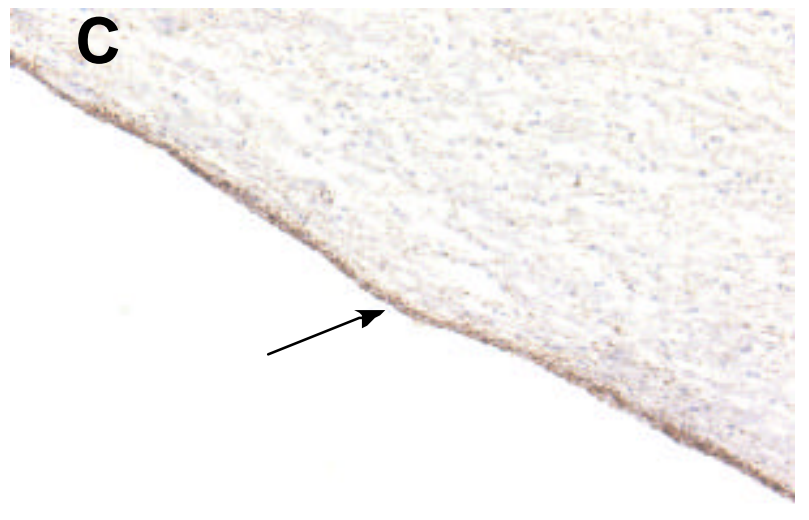

encoding methionine, or (C)GUG(G), encoding valine. Restriction endonuclease Bsa AI cleaves at CG, and thus does not cleave a 932 bp PCR product coding methionine at position 129 , but cleaves a PCR product coding valine into a $465 \mathrm{bp}$ and a $467 \mathrm{bp}$ fragment. Bsa AI was thus incubated with the purified PCR product, and the cleavage products separated on an agarose gel $(0.8 \mathrm{~g}$ agarose in $50 \mathrm{ml}$ TAE) in order to differentiate PCR products which had / had not been cleaved, and hence genotype each individual.

\section{RESULTS}

\section{Immunohistochemistry}

In each case of Alzheimer's disease $(n=10) \operatorname{Pr} P$ immunohistochemistry demonstrated PrP being expressed as globular deposits, which delineated structures resembling the $A \beta$ plaques of Alzheimer's disease (Fig.1). Immunostaining also showed deposition of SOD-1 at $A \beta$ plaques. Examining adjacent sections revealed that the PrP and SOD-1 immunostained plaques were distributed in a similar spatial pattern to the amyloid delineated by the anti$A \beta$ antibody. No neurofibrillary tangles were observed to immunostain for PrP. No neuronal somatic, microglial or astroglial immunoreactivity for PrP was detected. However, ependymal cells (morphologically identified) lining the lateral ventricle were observed to accumulate $\operatorname{PrP}$ (Fig.1). No PrP immunostaining was demonstrated in the young control cases, though PrP immunoreactive plaques were seen in an aged control (66 years).

\section{Western Blotting}

SDS-PAGE produced two bands labelled by $3 \mathrm{~F} 4$ on Western blot, corresponding to the $34 \mathrm{kDa}$ diglycosylated and $28 \mathrm{kDa}$ monoglycosylated $\mathrm{PrP}$ glycoforms found in non-diseased brain (Fig.2). Treatment with Proteinase K $(1 \mu \mathrm{g} / \mathrm{ml})$ digested PrP present in the Alzheimer's disease samples completely (data not shown). Thus, the PrP expressed in Alzheimer's disease is not PrPSC. Deglycosylation with PNGase-F produced a single species of $\operatorname{PrP}$ with a molecular weight corresponding to the unglycosylated glycoform of $\operatorname{PrP}$, indicating that $\operatorname{PrP}$ expressed in Alzheimer's disease is composed of the 208 residue peptide expressed in non-diseased brain tissue (data not shown).

\section{Semi-Quantitative Western Blotting}

The optical density of the PrP bands produced by Western blotting on an autorad film differed between each case of Alzheimer's disease and normal brain (Fig.2). Optical density reflects the amount of protein detected by primary antibody in a sample, and, as total protein in each sample had been normalised, the differing optical densities indicate different levels of PrP in each case. With cases one and two displaying absent PrP, cases three - six reduced levels of PrP 


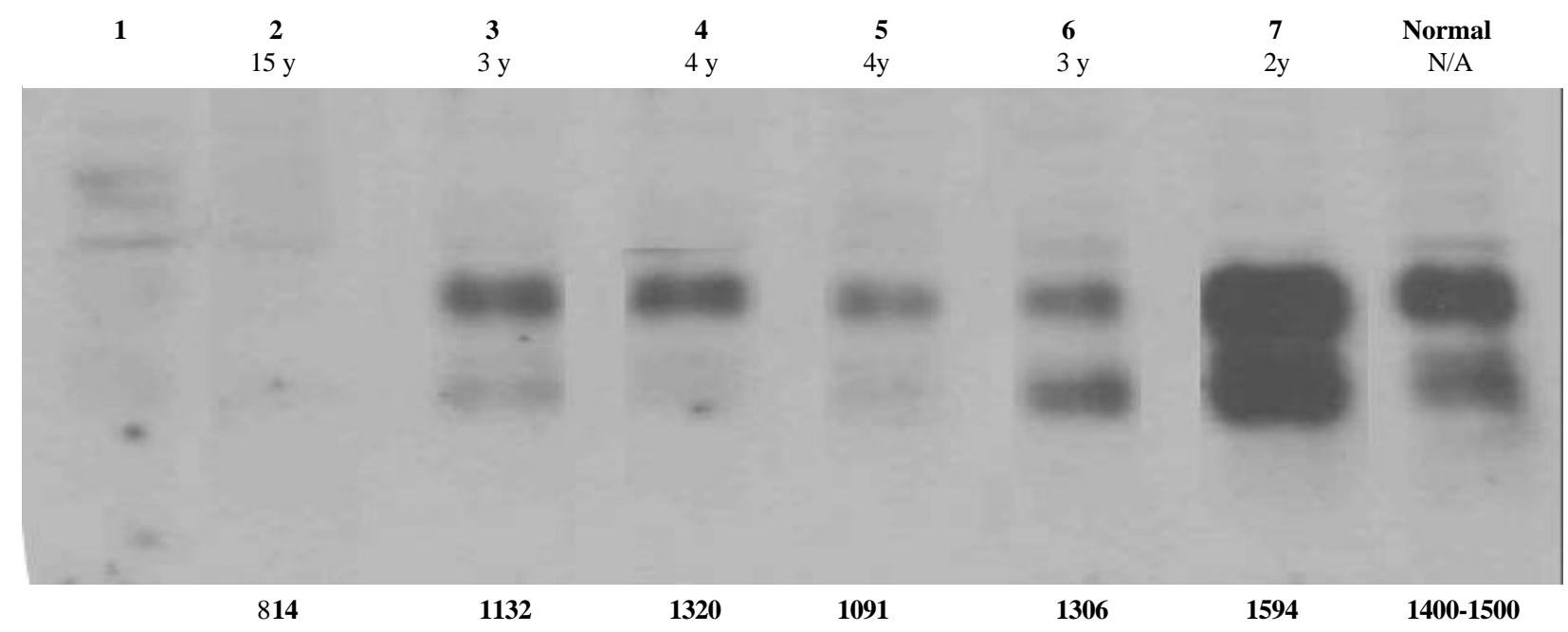

Figure 2. Quantitative Western Blot showing differential expression of PrP in $\mathrm{AD}$ and normal hippocampus. Lanes 1 - 7 contain $\mathrm{AD}$ tissue with normal tissue in lane 8. The case number, in bold, and disease duration, in italics, are tabulated above each lane with brain mass ( $\mathrm{g}$ ) below each lane. Blank = data unavailable. (The lanes in this image were rearranged from the original blot, so as to be in numerical order by case number.)

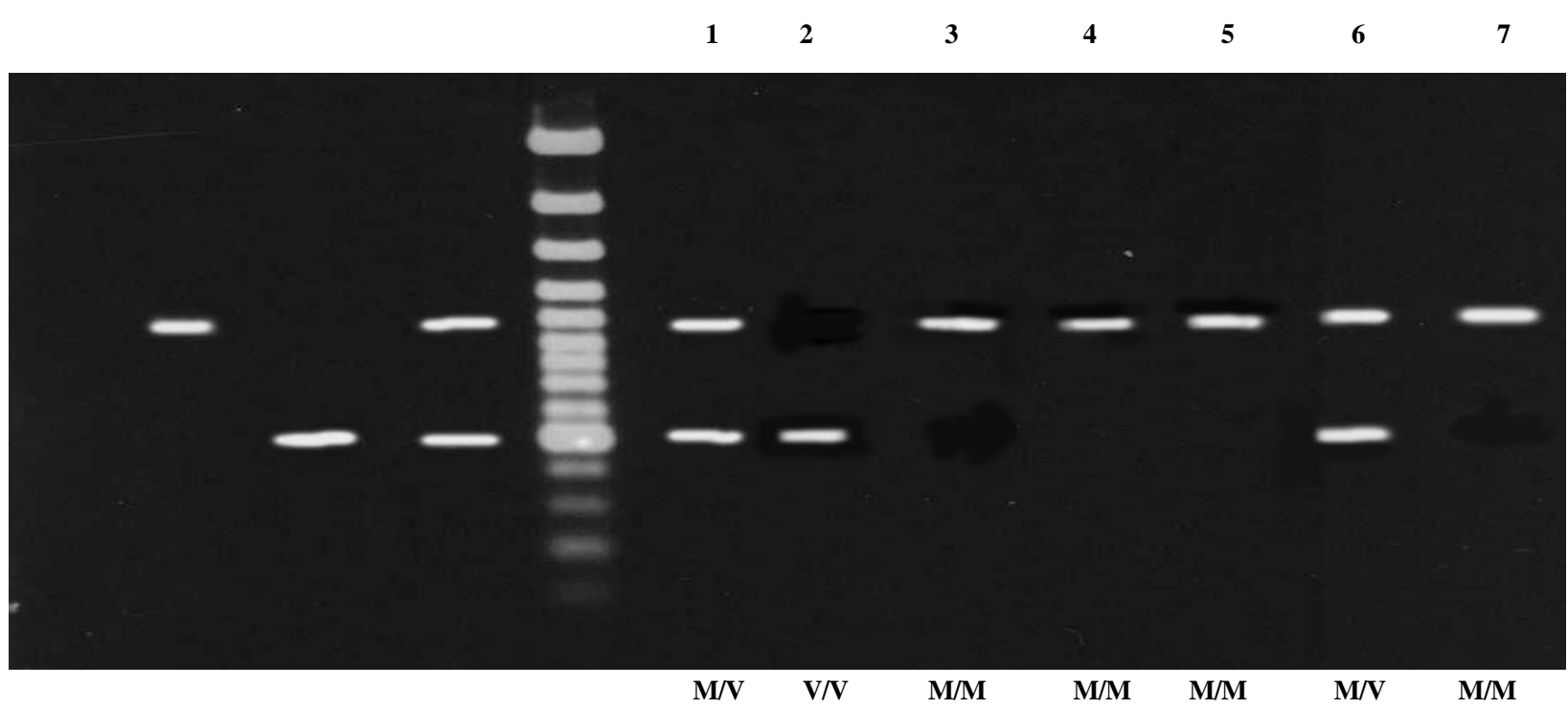

Figure 3. RFLP analysis of codon 129 polymorphism. Lanes 1 - 3 contain control DNA, Lane 1 shows the banding pattern of methionine homozygotes, lane 2 a valine homozygote, and 3 a heterozygote. The lanes to the right of the markers contain AD DNA, the case number is above each lane, and genotype below. (The lanes in this image were rearranged from the original blot, so as to be in numerical order by case number.)

compared with normal brain, and case seven elevated levels of PrP compared with control (Table 3). Normal brain consisted of hippocampal tissue from a cerebrum that did not manifest histopathological abnormalities.

\section{Codon 129 Genotyping}

Restriction Fragment Length Polymorphism genotyping demonstrated that all codon 129 (MM, MV, VV) genotypes were represented in the study cohort (Fig.3). Cases one and six being heterozygous, cases three - five and seven being methionine homozygotes, and case two a valine homozygote.
The ratio of genotypes in the study cohort is comparable with that in the general population (1).

\section{DISCUSSION}

The biological function of PrPC remains incompletely understood. However, in vitro studies demonstrating a SOD-like anti-oxidant activity of PrPC have lead to the hypothesis that cellular prion protein may help to protect neurons from oxidative damage $(5,6)$. In this study we sought in vivo evidence of a SOD-activity of PrPC by investigating the proposal that $\operatorname{PrP}$ deposition at $\mathrm{A} \beta$ plaques in $\mathrm{AD}$ reflects an anti-oxidant function of PrPC. For PrP 
Table3. Optical Densities Of Prion Protein Bands

\begin{tabular}{llll}
\hline Case & Diglycosylated & Monoglycosylated & Unglycosylated \\
\hline 1 & 0 & 0 & 0 \\
2 & 0 & 0 & 0 \\
3 & 0.68 & 0.18 & 0 \\
4 & 0.67 & 0.11 & 0 \\
5 & 0.34 & 0.08 & 0 \\
6 & 0.42 & 0.5 & 0 \\
7 & 1.92 & 1.71 & 0 \\
\hline Normal & 1.29 & 0.61 & 0 \\
\hline
\end{tabular}

expression in $\mathrm{AD}$ to give in vivo evidence supporting an anti-oxidant function of PrPC we believed that the following conditions should be met: 1 . PrP at $A \beta$ plaques must not be PrPSC (the PrP isoform found in Prion disease), 2. the pattern of PrPC deposition should resemble that of proteins (SOD-1) known to be upregulated by neuronal stress in $\mathrm{AD}$, and 3. PrP expression at $A \beta$ plaques must not be restricted to rare subtypes of AD. Our Western blot analysis fulfils the first criterion, as it demonstrated PrP in AD to have the characteristics of PrPC (mono- and diglycosylated glycoforms present, 208 amino acids long, proteinase $\mathrm{K}$ sensitive) (1). Evidence relating to points 2 and 3 is discussed below.

The topology of PrP deposition demonstrated by our immunohistochemical study is compatible with an anti-oxidant function for PrPC. Firstly, assuming PrPC at A plaques is accumulating within neuronal processes, PrPC is probably being expressed within neurons exposed to oxidative stress, since $A \beta$ plaques are associated with oxidative damage to adjacent neuronal processes (13). Moreover, the fact that the pattern of PrPC expression resembled that of SOD-1 supports the contention that $\operatorname{PrPC}$ is upregulated by neuronal stress in $\mathrm{AD}$, since neuronal SOD-1 has been shown to be induced by ROS generated by the $A \beta$ peptide $(14,15)$. The significance of ependymal accumulation of $\operatorname{PrP}$ is uncertain. However, it correlates with in situ hybridisation studies showing PrP mRNA expression in ependymal cells (16), and may reflect a response to ROS within cerebrospinal fluid in AD brain.

An alternative explanation for PrP immunostaining of $\mathrm{A}$ plaques in $\mathrm{AD}$ is that it is a feature of atypical neuropathogenesis in a rare subtype of $\operatorname{AD}(11,17,18)$. Evidence for this proposal comes from a pathological study that demonstrated $\operatorname{PrP}$ deposition at $\mathrm{A} \beta$ plaques using an antibody which was claimed to be specific for PrPSC (11). Furthermore, research demonstrating that valine homozygosity at codon 129 of PRNP increases risk of early onset AD (10), combined with reports of PRNP mutations in an FAD kindred (9), lends credence to the proposal that there may be a subtype of $\mathrm{AD}$ in which prion protein plays a pathogenic role. However, several factors argue against the PrP immunostaining in our study representing atypical neuropathogenesis. Firstly, our study contained sporadic $(n=9)$ and familial $(n=1)$ cases with a wide range of ages (42 - 90 years old), making it likely our cohort represented a spectrum of AD cases. Furthermore, though it was not possible to screen for PRNP mutations in our study, RFLP genotyping demonstrated that all PRNP codon 129 genotypes were represented in our cohort - suggesting that this polymorphism does not influence PrPC upregulation in $\mathrm{AD}$. Taken together, our results argue that PrPC immunostaining in our study is not part of the primary pathologic processes in $A D$, but secondary to deposition of A $\beta$-peptide, possibly reflecting an anti-oxidant action of PrPC.

In this study we hypothesised that immunohistochemical detection of PrP in Alzheimer's disease might reflect either elevated levels of PrP accumulating at amyloid plaques, or the synthesis of a putative, bioactive PrP which was structurally distinct from, and more immunoreactive than, PrPC. Western blotting provided no evidence of a novel $\operatorname{PrP}$ expressed at $A \beta$ plaques, as the molecular characteristics of PrP in Alzheimer's disease are indistinguishable from PrPC present in normal brain. However, semi-quantitative Western blot analysis showing differential levels of PrP expression in each case of Alzheimer's disease compared with nondiseased brain (Figure 2); suggestive of increased levels of PrPC in Alzheimer's disease. With reference to Figure 2, it can be seen that levels of PrP detected on Western blot decrease in parallel with increasing disease duration and neuronal loss (evidenced by decreasing brain mass). Thus, case 7 (normal brain mass) has supra-normal levels of PrP on densitometry, while cases 1 - 6 (brain mass: 814 - 1306g) have decreased levels of PrP compared with nonpathological brain. This suggests that there may be increased levels of PrP within individual cells, but with advancing disease duration, and increasing neuronal loss (12), there is a subnormal quantity of PrP at the tissue level. A caveat must be attached to this conclusion. Western blotting measures protein levels in a volume of tissue, but does not enable identification of what cells/structures contain the protein. Though, as PrPC is considered to be predominantly expressed in neurons (1), it is reasonable to suggest that the increased PrPC levels reflect neuronal PrPC. Even if elevated levels of PrPC in AD tissue were due to upregulation in nonneuronal cells, it would not invalidate the proposed 
SOD-like function of PrPC as the protein may also play an anti-oxidant role in glia and other nonneuronal elements. Though our study methodology had limitations, other techniques would not be able to provide proof of increased PrP protein or mRNA. For example, in situ hybridisation would not be helpful as a cell can express mRNA without protein, while Northern blotting would not permit examination of mRNA expression at the level of single cells. Attempting to demonstrate increased levels of PrPC protein in AD by counting cells has been performed previously, without definitive conclusions (7).

This apparent increase in levels of PrPC observed in $\mathrm{AD}$ tissue could be accounted for by two nonmutually exclusive mechanisms. Firstly, increased production of PrPC, via either elevated mRNA transcription/translation or reduced PrPC degradation, could result in accumulation of PrPC within neuronal processes at $\mathrm{A} \beta$ plaques. Alternatively, the $\operatorname{PrP}$ visualised at $A \beta$ plaques may represent extracellular protein that has "nucleated" around fibrillar $A \beta$ peptides within amyloid plaques (18). The study of Voigtlander and colleagues (7), which demonstrated significantly increased numbers of PrPC immunostained neurons in hippocampal tissue from AD brains, lends support to the former hypothesis, as it suggests increased synthesis of PrPC in AD. Nevertheless, before PrP nucleation at $\mathrm{A} \beta$-amyloid can be discounted, appropriate immunoprecipitation studies must be performed.

It is important to note the limitations that the small sample size places on our study. Firstly, if there is a subgroup of AD that does not express PrPC then our study may have been too small to detect this. In corollary, our small sample of PrPC expressing AD cases may represent a minority of cases which immunostain for PrPC. The factors noted above militate against these suggestions. Moreover, in our small study it was not possible to examine if the codon 129 genotype had any influence on factors such as extent of $A \beta$ plaque deposition or any influence on the clinical course of AD (disease duration etc). The relationship between disease duration and PrPC levels on semi-quantitative western blot also needs to be confirmed by examining a large cohort of cases with well defined short, medium and long disease durations.

In summary, this study has expanded upon previous reports of PrP expression in AD by showing that PrPC deposition at A plaques parallels deposition of SOD1 , by demonstrating that PrP expression is not limited to rare subtypes of $\mathrm{AD}$ and by providing evidence to suggest that levels of PrPC are elevated in AD. However, in concluding, certain factors, which might potentially confound our results, must be acknowledged. For example, since deposition of certain synaptic vesicle proteins at $\mathrm{A} \beta$ plaques occurs due to cytoskeletal disruption (20), PrPC immunostaining in Alzheimer's disease might merely represent a passive result of disrupted protein trafficking and endocytosis rather than an induced response to stress. This deranged protein trafficking and metabolism in moribund Alzheimer's neurons might, in theory, also account for the differential levels of PrP detected on Western blot in the cases examined. Nonetheless, it seems reasonable to conclude that accumulation of PrPC at $A \beta$ plaques in $\mathrm{AD}$ reflects a physiological function of PrPC. The precise biological activity of PrPC in AD brain cannot be elucidated from our results. However, given in vitro evidence of an anti-oxidant activity of PrPC $(5,6)$, and the similar immunostaining patterns of PrPC and SOD-1, an anti-oxidant enzyme which is induced by ROS produced by A -peptide $(14,15)$, it is possible PrPC expression in AD represents a role for the protein in the neuronal response to oxidative stress. In this respect, it is interesting to note that some in vitro studies have suggested PrPC might act as a co-factor for SOD-1 (6). If PrPC is a neuroprotective anti-oxidant protein which is upregulated by oxidative stress then it could have an important role in multiple neurodegenerative disorders, possibly acting to slow neuronal death and clinical deterioration. This hypothesis is supported by the study of Kovacs and associates (21), which showed increased neuronal immunoreactivity for PrPC in Multiple Systems Atrophy, Progressive Supranuclear Palsy and Motor Neuron Disease, as well as by research indicating that the codon 129 polymorphism predisposes to early onset $A D$ and modulates rate of cognitive decline in established $\mathrm{AD}$ (10). The hypothesis that PrPC has a neuroprotective function has obvious implications for Prion disease, as oxidative stress induced by PrPSC will upregulate PrPC and provide more substrate for toxic PrPSC production, which, in turn, leaves neurons vulnerable to damage by depriving them of a protective protein. Should the foregoing proposals prove correct then anti-oxidant therapy may provide a valuable neuroprotective strategy for Prion disease.

\section{REFERENCES}

1. Ironside JW. Prion Diseases In Man. Journal of Pathology 186(3):227-234; 1998.

2. Collinge J, Whittington MA, Sidle KC, et al. Prion Protein Is Necessary For Normal Synaptic Function. Nature 370(6487):295-297; 1994.

3. Herms J, Tings T, Gall S, et al. Evidence Of Presynaptic Location And Function Of The Prion Protein. Journal of Neuroscience 19(20): 8866-8875; 1999. 
4. Moore RC, Lee IY, Silverman GL, et al. Ataxia In Prion Protein Deficient Mice Is Associated With Upregulation Of The Novel PrP - Like Protein Doppel. Journal of Molecular Biology 292(4):797-817; 1999.

5. Brown DR, Besinger A. Prion Protein And Superoxide Dismutase Activity. Biochemical Journal 334:423-429; 1998.

6. Brown DR, Schulz - Schaeffer WJ, Schmidt B, Kretzschmar HA. Prion Protein Deficient Cells Show Altered Response To Oxidative Stress Due To Decreased SOD -1 Activity. Experimental Neurology 146(1):104-112; 1997.

7. Voigtlander T, Kloppel S, Birner P, et al. Marked Increase Of Neuronal Prion Protein Immunoreactivity In Alzheimer's Disease And Human Prion Diseases. Acta Neuropathologica 101(5):417-423; 2001.

8. Ferrer I, Blanco R, Carmona $\mathrm{M}$, et al. Prion Protein Expression In Senile Plaques In Alzheimer's Disease. Acta Neuropathologica 101(1):49-56; 2001.

9. Perry RT, Go RCP, Harrell LE, et al. SSCP Analysis And Sequencing Of The Prion Protein Gene Detects Two 24 bp Deletions In An Atypical Alzheimer's Disease Family. American Journal of Medical Genetics 60(1):12-18; 1995.

10. Casadei VM, Ferri C, Calabrese E, et al. Prion Protein Gene Polymorphism And Alzheimer's Disease: One Modulatory Trait of Cognitive Decline? Journal of Neurology, Neurosurgery and Psychiatry 71(2):279-280; 2001

11. Leuba G, Saini K, Savioz A, Charnay Y. Early Onset Familial Alzheimer Disease With Co-existing -Amyloid And Prion Pathology. Journal of the American Medical Association 283(13):756; 2000.

12. Graham DI, Lantos PL. Ageing And Dementia. In: Graham DI, Lantos PL, eds. Greenfield's Neuropathology. London: Arnold, 1997.

13. Lyras L, Cairns NJ, Jenner A, Jenner P, Halliwell B. An Assessment Of Oxidative Damage To Proteins, Lipids, And
DNA In Brain From Patients With Alzheimer's Disease. Journal of Neurochemistry 68(5):2061-2069; 1997.

14. Yatin SM, Aksenova M, Aksenov M, et al. Temporal relations among amyloid beta-peptide-induced free-radical oxidative stress, neuronal toxicity, and neuronal defensive responses. Journal of Molecular Neuroscience 11(3):183-97; 1998.

15. Celsi F, Ferri A, Casciati A, et al. Overexpression of SOD-1 Protects Against -Amyloid Peptide Toxicity: Effect of Oestrogen and Copper Chelators. Neurochemistry International 44(1):25-33; 2004.

16. McLennan NF, Rennison KA, Bell JE, Ironside JW. In Situ Hybridisation Analysis Of PrP mRNA In Human CNS Tissue. Neuropath. Applied Neurobiology 27(5):373-383; 2001.

17. DeArmond SJ. Alzheimer's Disease and Creutzfeldt-Jakob Disease: Overlap Of Pathogenic Mechanisms. Currents Opinions in Neurology 6(6):872-881; 1993.

18. Hainfellner JA, Wanschitz J, Jellinger K, Liberski PP, Gullotta F, Budka H. Coexistance Of Alzheimer-Type Neuropathology In Creutzfeldt Jakob Disease. Acta Neuropathologica 96(2):116-122; 1998.

19. Forloni G, Tagliavini F, Bugiani O, Salmona M. Amyloid in Alzheimer's Disease And Prion Related Encephalopathies: Studies With Synthetic Peptides. Progress in Neurobiology 49(4):287-315; 1996.

20. Dickson DW. The Pathogenesis of Senile Plaques. Journal of Neuropathology and Experimental Neurology 56(4):321-339; 1997.

21. Kovacs GG, Zerbi P, Voigtlander T, et al. The Prion Protein In Human Neurodegenerative Disorders. Neuroscience Letters 329(3):269-272; 2002.

Alisdair McNeill is currently a House Officer at Gartnavel General Hospital and the Western Infirmary Glasgow. His research interests are stroke, prion disease and neurologic education. He hopes to work as a Clinical Academic in Neurosciences 